
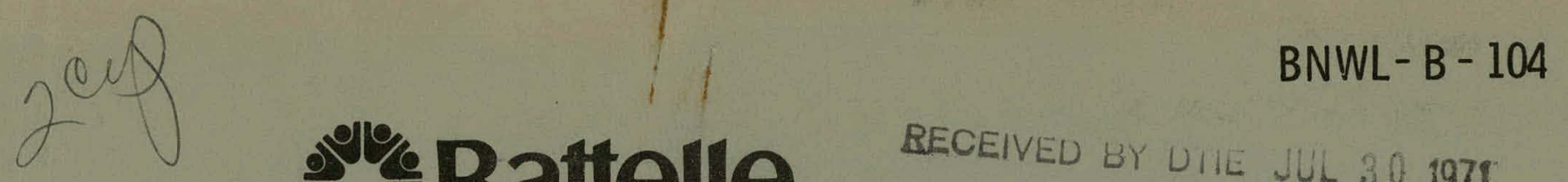

BNWL- B - 104

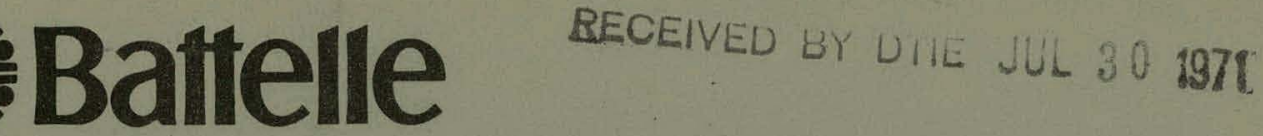

Pacific Northwest Laboratories

Richland, Washington 99352

This report is intended primarily for internal use

by the sponsoring organization and Battelle.

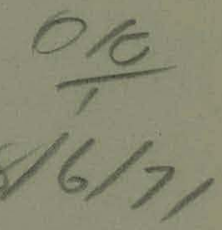

RADIOMETALLURGY

GAMMA SCANNING

SYSTEM

\section{K.L. SWINTH}

June 1971
THIS DOCUMENT CONFIRMED AS UNCLASSIFIED

DIVISION OF CLASSIFICATION

DA

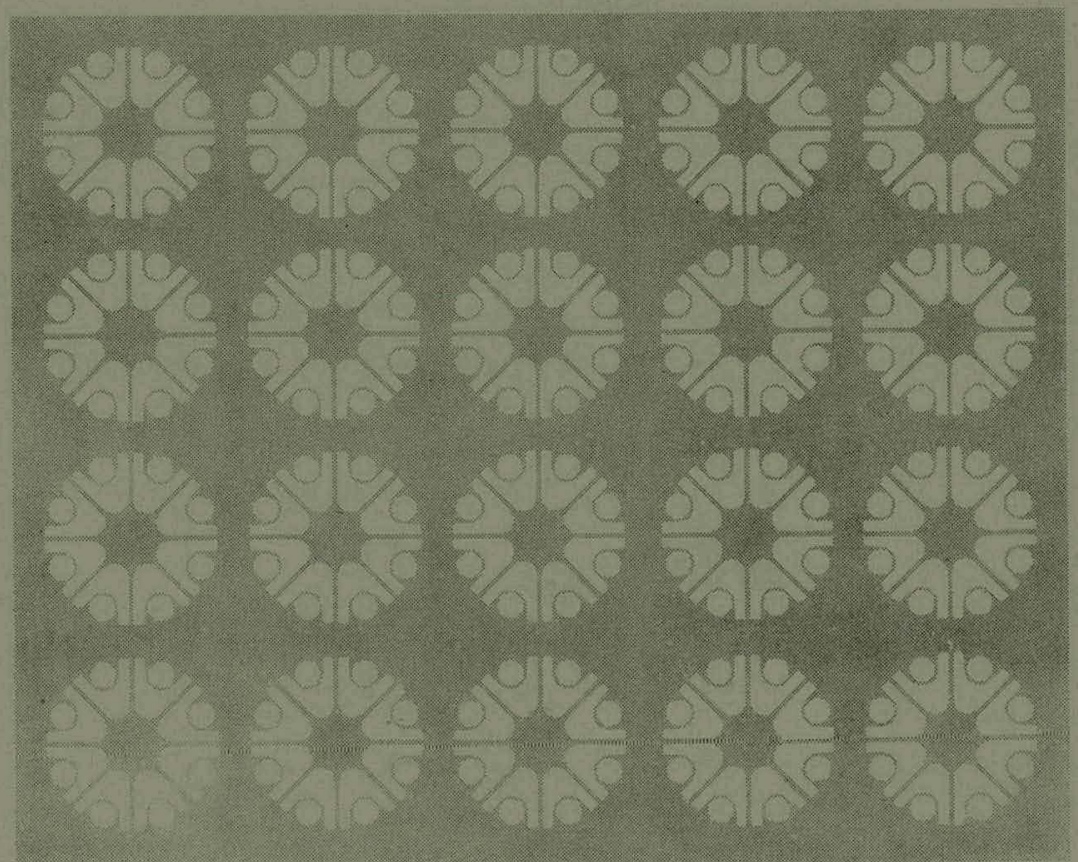




\section{DISCLAIMER}

This report was prepared as an account of work sponsored by an agency of the United States Government. Neither the United States Government nor any agency Thereof, nor any of their employees, makes any warranty, express or implied, or assumes any legal liability or responsibility for the accuracy, completeness, or usefulness of any information, apparatus, product, or process disclosed, or represents that its use would not infringe privately owned rights. Reference herein to any specific commercial product, process, or service by trade name, trademark, manufacturer, or otherwise does not necessarily constitute or imply its endorsement, recommendation, or favoring by the United States Government or any agency thereof. The views and opinions of authors expressed herein do not necessarily state or reflect those of the United States Government or any agency thereof. 


\section{DISCLAIMER}

Portions of this document may be illegible in electronic image products. Images are produced from the best available original document. 


\title{
NOTICE
}

This report was prepared as an account of work sponsored by the United States Government. Neither the United States nor the United States Atomic Energy Commission, nor any of their employees, makes any warranty. express or implied, or assumes any legal liability or responsibility for the accuracy, completeness or usefulness of any information, apparatus, product, or process disclosed, or represents that its use would not infringe privately-owned rights.

\author{
PACIFIC NORTHWEST LABORATORY \\ operated by \\ BATTELLE \\ for the \\ U.S. ATOMIC ENERGY COMMISSION \\ Under Contract AT(45-1)-1830
}




\section{RADIOMETALLURGY GAMMA SCANNING SYSTEM}

By

K. L. Swinth

Applied Physies and Instrumentation Department

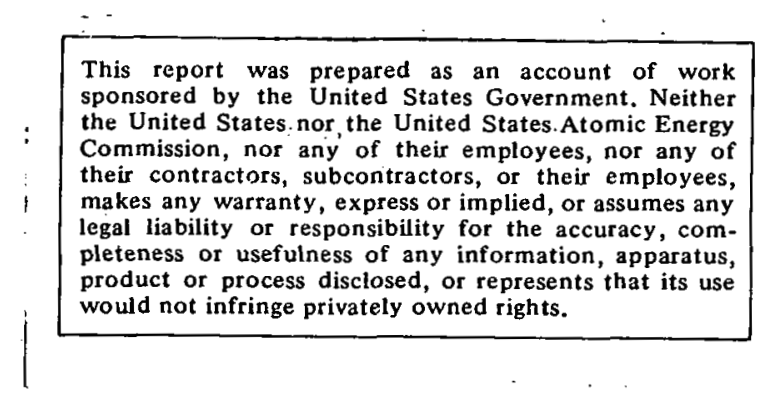

June 1971

THRESTRICTED

Jul 1679

DISTRUBUTION MADE

BATTELLE

PACIFIC NORTHWEST LABORATORIES

RICHLAND, WASHINGTON 99352 
RADIOMETALLURGY GAMMA SCANNING SYSTEM

K. L. Swinth

\section{ABSTRACT}

A versatile gamma scanning system has been designed and installed for the scanning of irradiated fuels. The system will collect continuous scan data, incremental scan data, and spectra at selected points. A general description of the system hardware and its operation are included in this report. Examples of typical data are used to demonstrate system operation. 


\title{
RADIOMETALLURGY GAMMA SCANNING SYSTEM
}

\author{
K. L. Swinth
}

\section{INTRODUCTION}

Gamma scanning is a nondestructive radiochemical analysis of a radiation emitting material (fuel pin) relative to position. The technique can range from a highly sophisticated point-by-point spectral analysis of the activity $(1,2,3)$ to a simple differential scan of gross activity. (4) This paper describes a system with an intermediate degree of sophistication which is useful for general gamma scanning of irradiated fuels. Included are descriptions of the facility established, its modes of operation, its limitations, and typical results.

The system described here reproduciblely and accurately moves the subject fuel pin past an area-defining slit. Activity from the examined area is detected by a high-resolution solid-state detector. The spectral data obtained can be then stored as gross activity versus position or as four specific energy groups versus position. A multichannel analyzer permits observation of spectral data along the fuel pin and adds versatility to the system. Data can be accumulated in three basic modes:

1) Continuous ratemeter scan

2) Incremental scan

3) Accumulation of spectra at selected areas.

The analyzer is bypassed in the first mode, while the other modes use the analyzer and the more powerful digital storage of information.

Fuel pins are moved digitally in 1.25 mil increments with the position information stored on scalars and referenced to limit switches on the scanner frame. 'lhe movement of the pin is alco used to control storage of data in the analyzer. 
The collected information can be used to determine the distribution of activity in the fuel rod and to infer the relative distribution of specific isotopes. This information can be used to measure fuel burnup, fuel dimen-sions, and power distribution. $(1,5,6)$ other quantities of interest may be inferred from the obtained information.

\section{MECHANICAL DESIGN}

\section{SCANNING MECHANISM}

The mechanical system was designed to move a cylindrical fuel element oriented vertically past a collimator containing a horizontal slit while working within the constraints of an available hot cell. Rods from 0.2 to 1.125 inches in diameter and up to 84 inches long can be scanned over a 50 inch active area. The rod is positioned on a movable carriage, held at one end by a collet in a rotatable holder and at the other end by a sliding tail stock. A movable steady rest is available to support the center of the fuel pin.

Figure 1 shows a photograph of the installed mechanical unit. The fuel pin can be rotated on its carriage as it is traversed. The carriage is supported by ball bushings and moved by a ball screw with a $1 / 4$ inch pitch. Axial motion is provided by a stepping motor while position is referenced to and limited by installed limit switches. Since the stepping motor rotates $1 / 200^{\text {th }}$ turn per pulse, the basic unit of axial motion is 0.00125 inch.

\section{COLLIMATORS}

Figure 2 shows the arrangement of collimators used for beam definition. The cullimators arc in a steel sleeve designed to fit in a standard hot cell access port. The sleeve is supported at the center and at the ends where movable supports are provided, thus allowing alignment of the sleeve. 


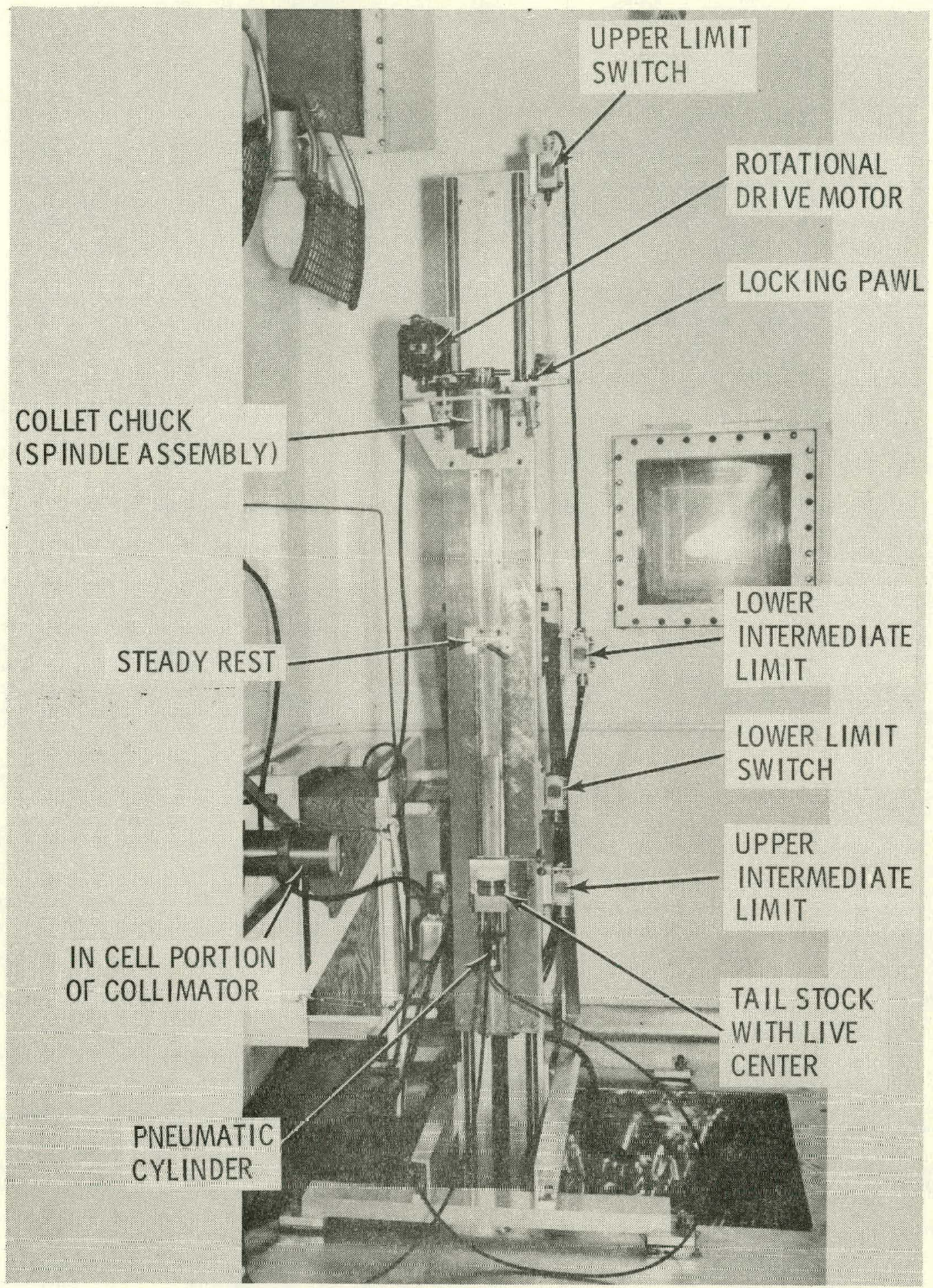

FIGURE 1. Mechanical Scanner in Hot Ce11. The drive motor is at the bottom of the pit below the scanner. 


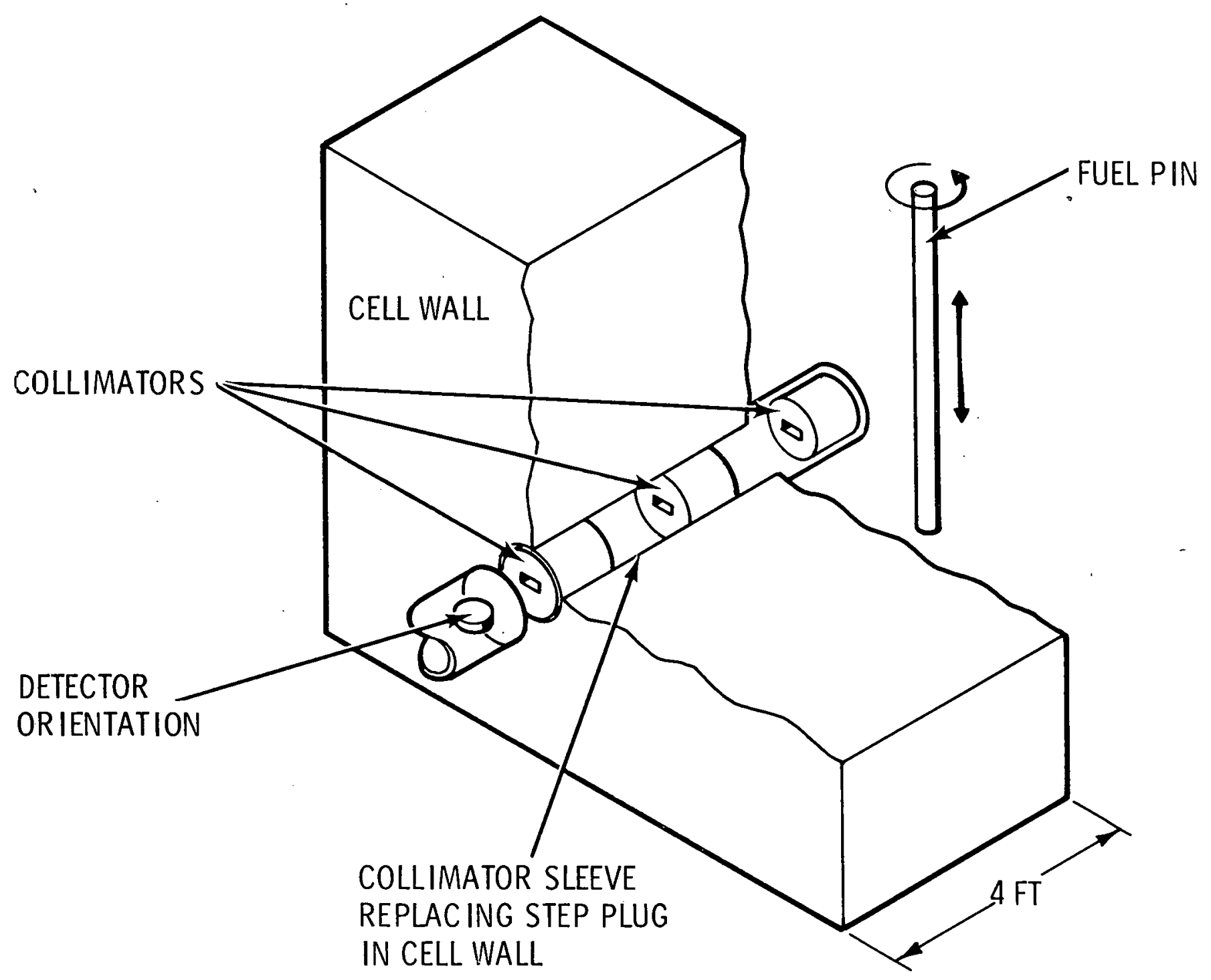


All of the collimators are lead and contain machined slits $1 / 2$ inch wide. The innermost collimator slit is $40 \mathrm{mils}$ high and is fixed while the other collimators slits can be changed. Changeable collimators 40 mils and 10 mils high were provided as judged by calculation from projected fuel activities; (7) experience to date has shown these collimators to be suitable for the activities encountered. The collimators are spaced for better beam definition, to keep unit weight manageable, and to distribute the weight over the three support points. Each collimator is a lead cylinder about 8 inches long and weighing approximately 40 pounds.

\section{DETECTOR}

The detector is a standard lithium-drifted planar detector mounted in a right angle dipstick cryostat. The detector $\left(11 \mathrm{~mm} \times 7.5 \mathrm{~cm}^{2}\right)$ is mounted with its flat area horizontal thus allowing maximum path length for the slit-defined beam (Figure 2). Detector resolution is $3.0 \mathrm{keV}$ at $1.33 \mathrm{MeV}$ and $2.25 \mathrm{keV}$ at $0.662 \mathrm{MeV}$.

Both the cryostat and associated liquid nitrogen dewar are supported in a box-like open frame which can be moved as a unit parallel to the face of the hot cell containing the pin and scanning apparatus. This permits the detector to be moved out of the way, allowing free access to the nearby in-cell manipulators. The frame also supports a lead shield around the detector and contains a mechanism for aligning the detector with the collimated beam from the fuel pin.

\section{ELECTRONIC DESIGN}

\section{GAMMÁ COUNTING ELECTRONICS}

The syctem ueed for gamma rnunting is a standard configuration centered around the planar lithium-drifted solid-state detector described in the previous sections. A block diagram in Figure 3 shows the overall relation of the various portions of the scanner. Pulses from the detector 


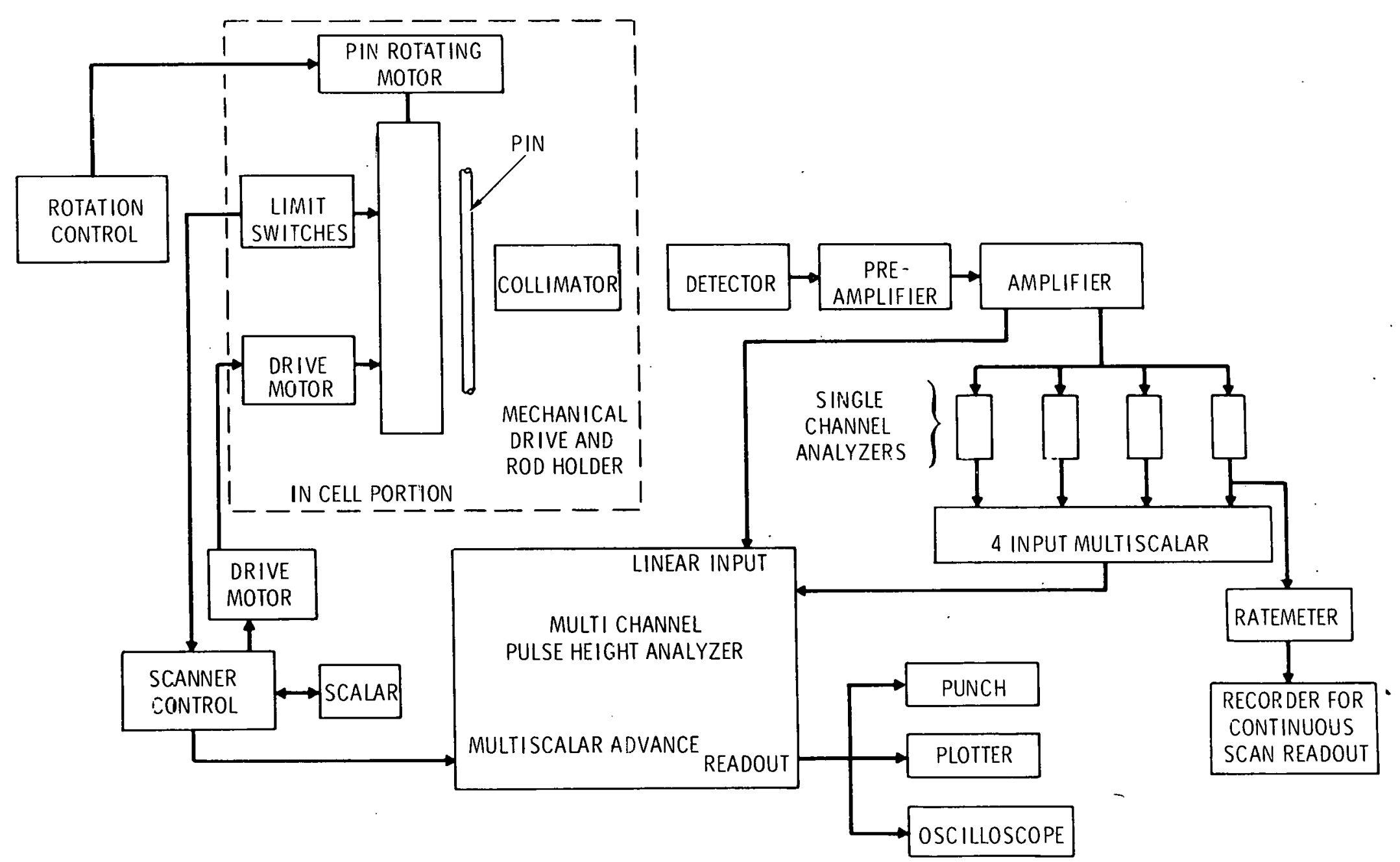

FIGURE 3. Schematic of Major Portions of Fuel Scanner Electronics and Their Interconnections 
are amplified in an FET preamplifier and then fed to an amplifier incorporating a base line restorer. The amplifier pulses go to a 2,048 channel pulse-height analyzer where data accumulation is in the spectral mode for selected points and in the multichannel scaling mode during scanning operations. Amplifier pulses are also routed to four, single-channel analyzers and a ratemeter. The outputs of the single-channel analyzers are used in a four-input multichannel scalar unit which routes the singlechannel data to the memory quadrants. The ratemeter output is used for a continuous chart recorder readout of single-channel data. This provides the three basic modes of data accumulation:

1) Continuous ratemeter scan

2) Incremental scan

3) Accumulation of spectra at selected points.

Data can be read out on a point plotting chart recorder, a continuous chart recorder (mode 1 ), or by a tape punch. Although the system was designed to provide primarily qualitative information, it is versatile and could be updated later.

\section{SCAN CONTROL ELECTRONICS}

Scan control is accomplished by one of two modules containing control circuits to regulate the axial scan operation of the scan mechanism and the channel advance of the multichannel scalar. Figure 4 shows a photograph nf nne of the control modules. The other module is a prototype of the module shown and is used as a standby. Controls allow selection of the scan speed, scan direction, scan increment and scan limits. Scan speeds are shown in Table 1. 


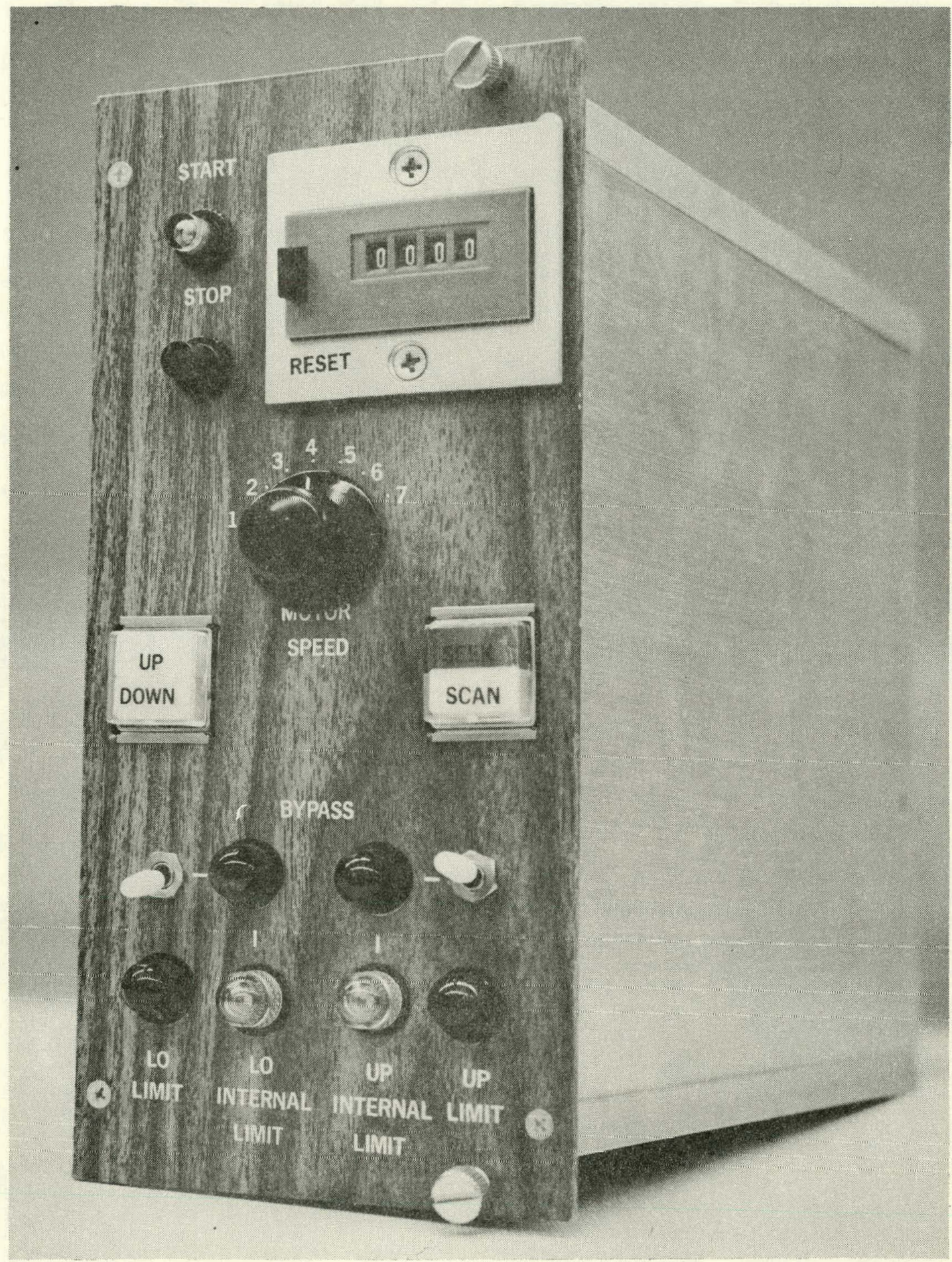

Neg 700518-9

FIGURE 4. Panel Layoul for Scanner Control Module 


\section{TABLE 1. Scan Speeds}

\begin{tabular}{ccc} 
Switch Position & \multicolumn{2}{c}{ Scan Speed, inches per minute } \\
\cline { 2 - 2 } 1 & $\frac{\text { Control No.1 }}{0.0448}$ & $\frac{\text { Control No. } 2}{20459}$ \\
2 & 0.0656 & 0.0681 \\
3 & 0.2050 & 0.2050 \\
4 & 0.3460 & 0.3460 \\
5 & 0.5450 & 0.5190 \\
6 & 1.2900 & 1.3100 \\
7 & 5.9200 & 5.9100
\end{tabular}

The scan increment is the number of 0.00125 inch steps taken during storage of counting data in the multichannel scalar (analyzer). The scan increment is selected by dialing the desired number of pulses into a preset scalar which counts the motor pulses. After the preset count is reached the control electronics reset the scalar, store a count in an electromagnetic totalizer and advance the multichannel scalar one channel where information is stored until the next time the preset count is reached. This sequence is stopped when a limit switch is reached or when the manual stop button is depressed. In either case, the total on the electromagnetic counter represents the number of channels advanced. The number of channels (increments) times the steps per increment indicates the total distance scanned.

The control module also has a seek operation used to locate a fixed position on the rod. During this operation the unit will drive the rod until a preset count is reached and then stop pending further action by the operator.

Limit switches are used as reference points. Figure 1 shows the relative location of the switches. The lower intermediate switch is triggered by the "tailstock" of the scanner at the level of the collimator. Since the tailstock is adjusted for the length of the rod, this position 
must be considered relative. The extreme limit switches are designed with interlocks requiring a reversal of motor direction before these switches can be overridden.

The scanner travels 50.82 inches between the upper and lower limit switches. Limit switch triggering points are very reproducible showing a standard deviation of \pm 5 mils ( \pm 4 pulses) for ten up and down trials at the maximum scan rate. When the lower limit switch is triggered, the collimator is viewing the bottom of the collet which can be considered a fixed reference point. When the lower intermediate switch is triggered the collimator is viewing a point about 20.1 inches below the collet. The triggering point for the upper intermediate switch varies in relation to the other switches since it is triggered by the movable tailstock. However, when it is triggered, the collimator is directed at a point about 4 inches above the live center. This position will vary slightly due to different degrees of extension in the pneumatic cylinder used to hold the live center against the pin. The intermediate limit switches are placed so that the full length of typical fuel rods will be scanned between these limits.

Figures $5 a$ and $5 b$ show the complete circuits of the two control modules.

\section{RESULTS}

\section{CONTINUOUS SCAN}

Continuous scanning using a ratemeter is the simplest method of fuel pin scanning. This mode of operation bypasses the major portion of electronics, using only the scan rate control feature of the scanner control. Direct interaction between the control mechanism and data storage (chart recorder) does not exist as can be seen on Figure 3. Figure 6 shows a typical continuous scan readout.

In the continuous scan mode, accuracy and resolution are limited by count rate, scan speed and collimation. At a high scan speed it is possible 


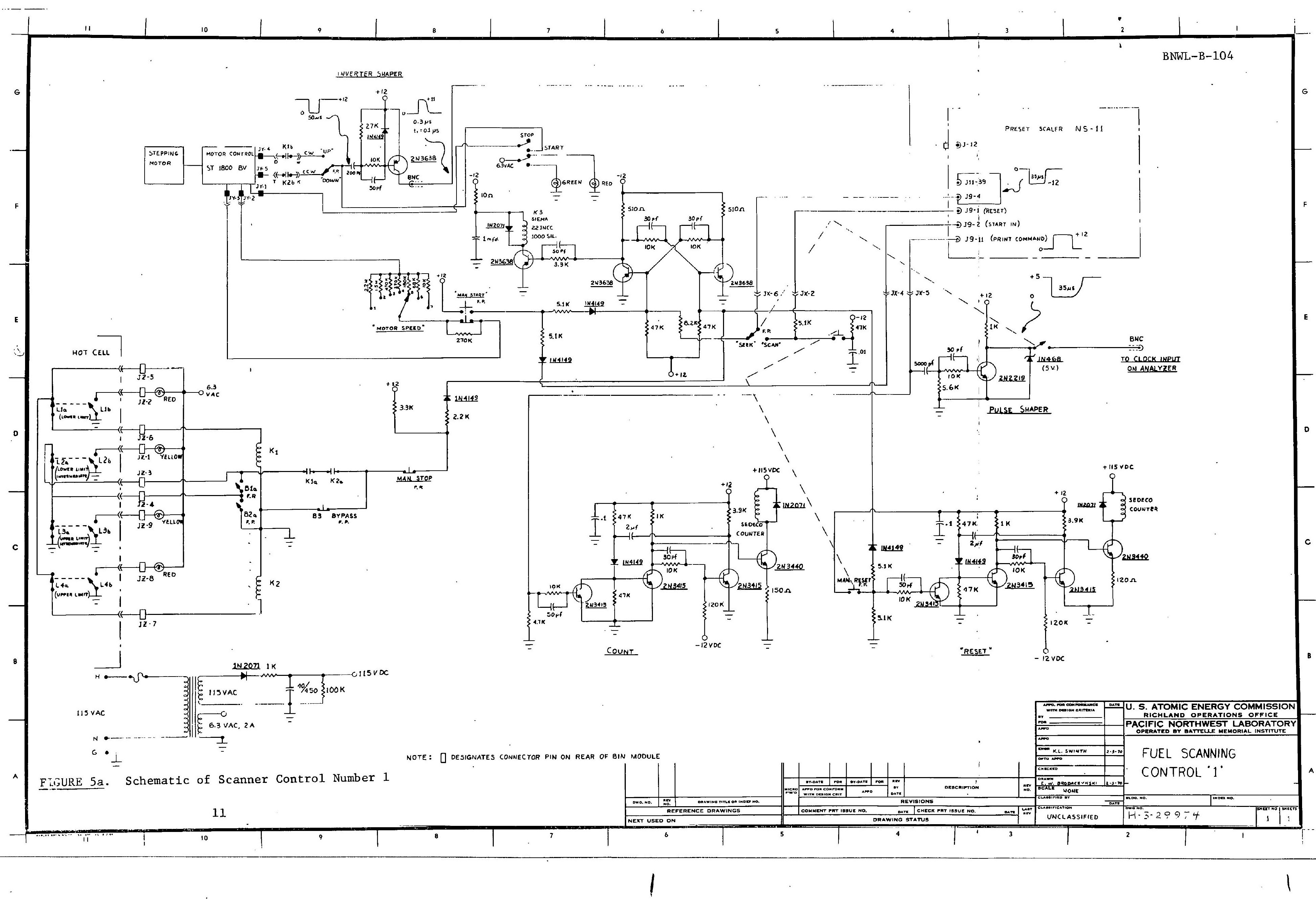




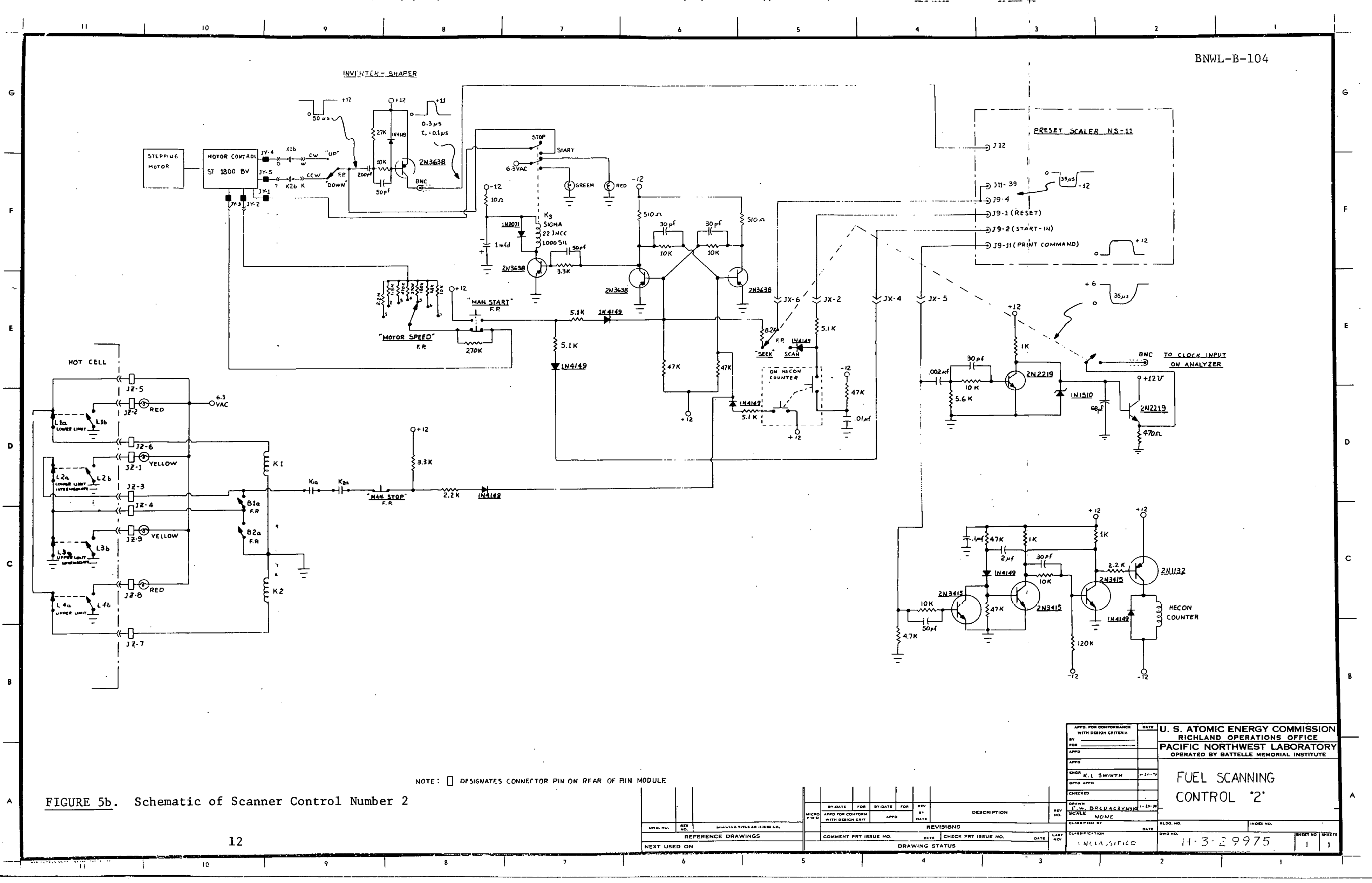




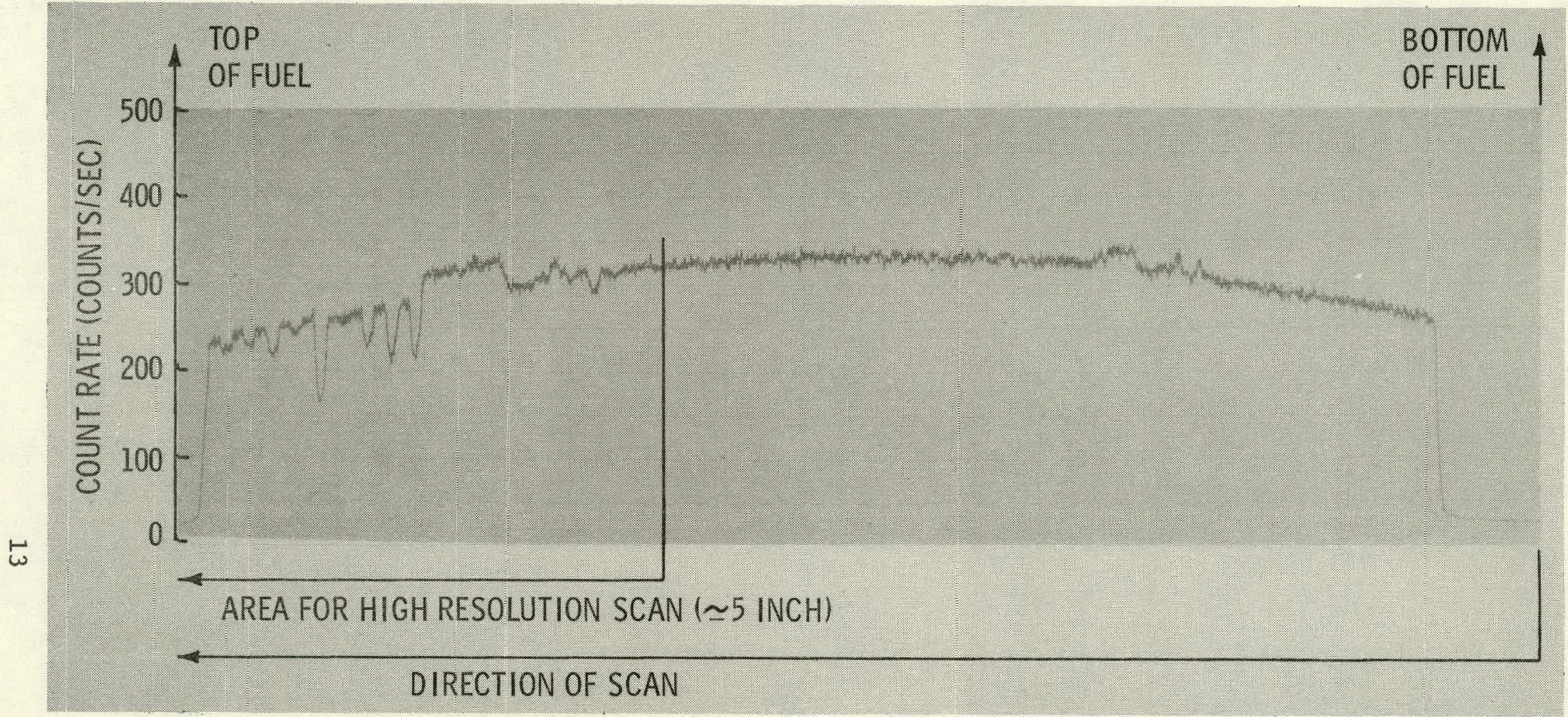

FIGURE 6. Gross Scan of PNL 7-10. Fuel length is $139 / 16$ inches with a scan length of 14.5 inches. Continuous ratemeter scan using $1 \%$ standard deviation and scan speed of $0.205 \mathrm{in.} / \mathrm{min}$ with $40 \mathrm{mil}$ collimator 
to achieve good statistical accuracy yet have point changes in count rate pass the collimator so rapidly that the system cannot respond. Requi.ring that a specific point remain within view of the collimator for two time constants one obtains the following formulas:

$$
\begin{aligned}
& \text { MSR }=0.6 \mathrm{f}^{2} \mathrm{r} \quad(10 \mathrm{mil} \text { collimator }) \\
& \text { MSR }=2.4 \mathrm{f}^{2} \mathrm{r} \quad(40 \mathrm{mil} \text { collimator })
\end{aligned}
$$

where:

$$
\begin{aligned}
\text { MSR } & =\text { maximum scan rate (inches } / \text { minute) } \\
\mathrm{f} & =\text { fractional error desired }(i . e ., 0.01=1 \%) \\
r & =\text { count rate }(\mathrm{cps} ; \text { counts } / \mathrm{sec}) .
\end{aligned}
$$

This formula gives the maximum scan speed at a given count rate if we select a particular fractional error and require that a point on the rod traverse the collimator in greater than two time constants. Count rate changes at the level of the fractional error would be impossible to pick out of the noise. Count rate resolution is best taken as about three times the fractional error while spatial resolution is limited by the collimator width. Scan speeds greater than the MSR will tend to "bury" the smaller changes in the statistical noise.

\section{INCREMENTAL SCAN}

In incremental scanning the activity from a segment of the fuel pin is integrated and stored in the analyzer memory. Progressive analyzer channels contain the information from progressive areas along the pin. This method is more powerful than the continuous scan since the integration area (statistical accuracy) is selected by integrating a certain distance along the rod rather than using an electronic time constant. In addition, data are available in digital form for computer analysis. If the distance integrated along the rod is the same as the collimator width, the formulas in the previous section apply. However, with a 14 inch scan length and storage of four energy intervals, the maximum scan rate is three times that predicted by the formula for the $10 \mathrm{mil}$ collimator and the distance for 
integration would be 27.5 mils (22 steps). Distance resolution will be approximately the scan interval while "contrast" resolution (change in counts) will be about three times the standard deviation of the accumulated count. A little thought will show that it is possible to resolve and locate detail smaller than the collimator width provided the "contrast" is great enough. This requires an integration interval smaller than the collimator width and such practices are limited by the available memory and the time needed for the slow scans.

Figure 7 shows a typical spectrum for a fuel pin and indicates areas integrated for a four input scan. The windows can be set for the singlechannel analyzers (SCA) by simply using the SCA output to gate the analyzer in coincidence and then by observing the region of storage. One must use the minimum SCA window possible to exclude as many background counts as possible. The peaks ride on a background which will "average out" peak intensity variations and will also contribute to the variations attributed to the peak. A second window placed on the continuum adjacent to the peak window can be used to correct for the background variations.

Figure 8 shows an incremental scan of the energy regions shown in Figure 7 and includes the area indicated on the continuous scan (Figure 6). This was done at the slowest scan speed (0.0459 in/min.) and with the collimator and integration intervals held equal (10 mils). A drop in count rate can be observed between pellets, the spacing of which can be obtained from the scans. An average of four of the depressions between pellets yields a spacing of $255 \mathrm{mils}$. If the pins were to get thermally hot enough for ${ }^{137} \mathrm{Cs}$ migration $\left(2000{ }^{\circ} \mathrm{C}\right)$ one should observe peaks in the ${ }^{137} \mathrm{Cs}$ activity between the pellets. (5) However, the present data is not statistically precise enough to make any statements. Such an analysis. would require considerably slower scan speeds than presently available. 


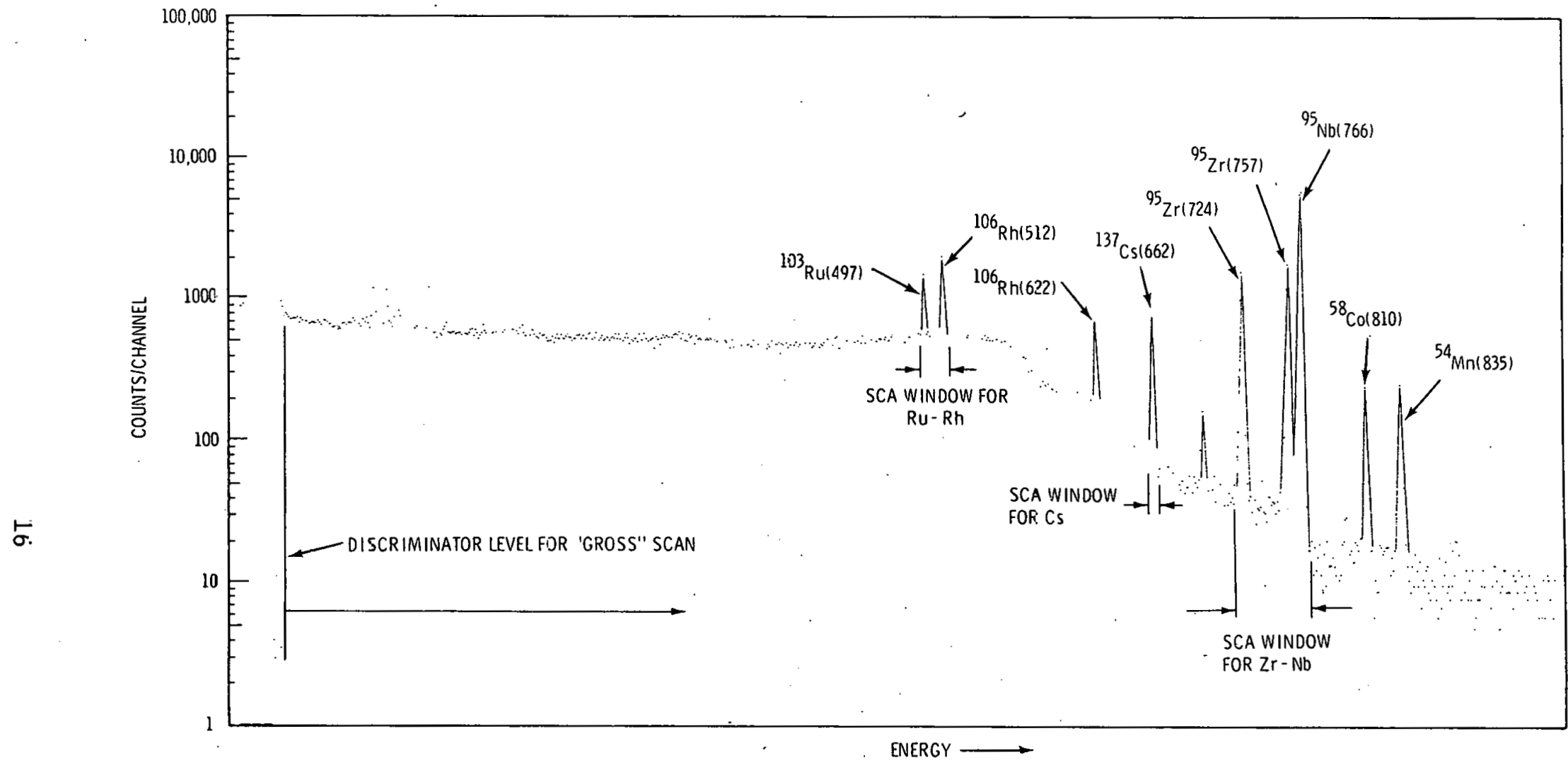

FIGURE 7. Spectrum of PNL 7-10 Showing Major Photopeaks (energies in parenthesis, keV) and Energy Intervals Used in Scanning 


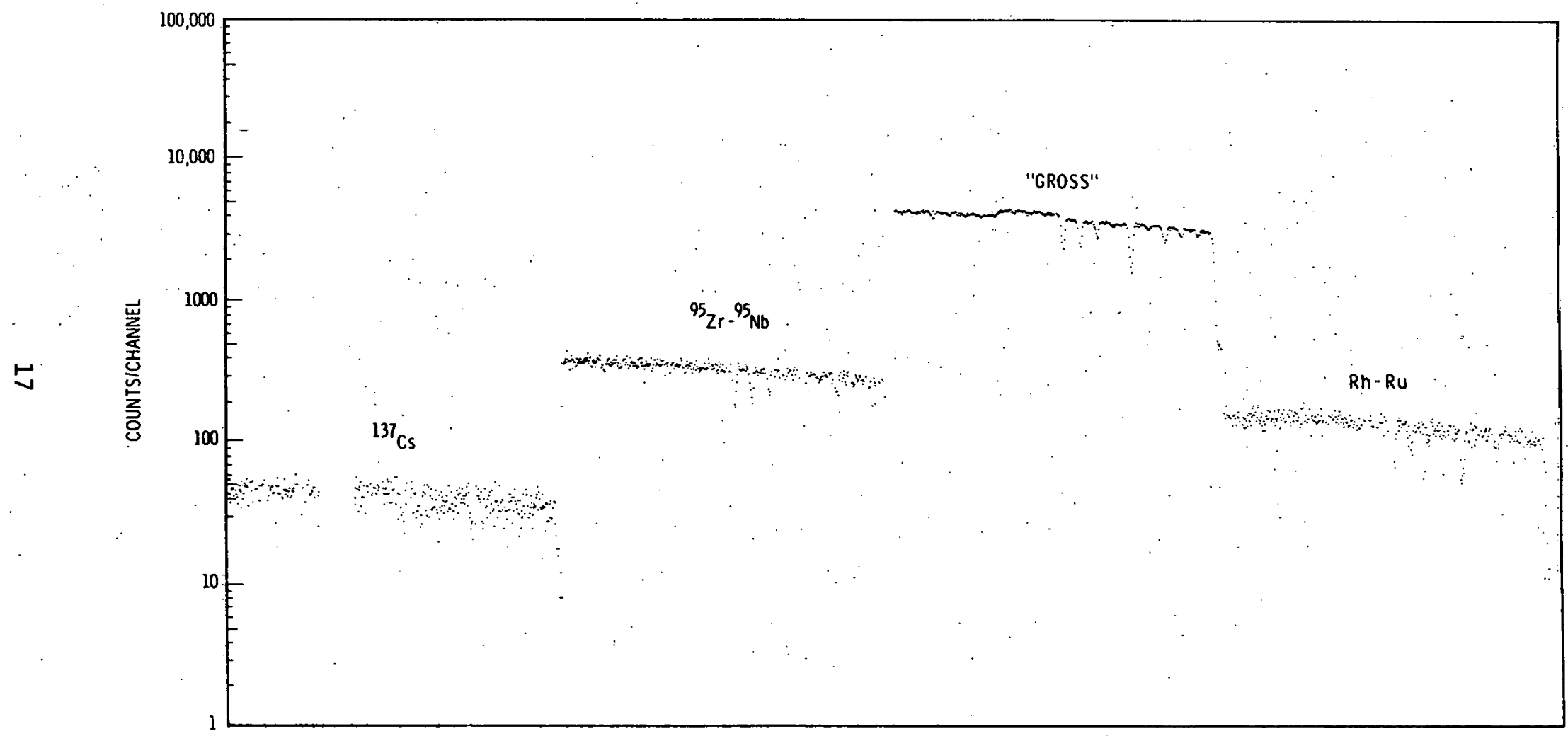

DISTANCE ALONG FUEL ELEMENT

FIGURE 8. Scan of Lower Portion of PNL 7-10 at 0.0459 in./min.with 10 mil Collimator and 10 mil Scan Interval (each point represents 10 mils) 


\section{POINT-BY-POINT SPECTRA}

The system can also take spectra at selected points along a pin for computer analysis or qualitative comparisons. Figure 7 shows a typical spectrum and Figure $9^{(6)}$ shows a series of such spectra taken along a fuel pin.

\section{CONCLUSIONS AND RECOMMENDATIONS}

The purpose of this report has been to record design features of the gamma scanner and point out some modes of operation. Data analysis is a separate and complex problem. Reference 6 presents some data and results collected with the described system.

The system has met its design requirements of versatility and simplicity of basic operation. By addition of further electronics, the system can be adapted to perform analysis as precise and complex as any other systems in use. (1) Although the system presents a wealth of qualitative data, the data are available in a form useful for computer analysis.

Recommendations would include the following changes or additions: (1) Use a shaft encoder for position control and to replace the limit switches, (2) Add a pulse divider or separate pulse generator to allow ultra-slow scanning, and (3) Develop analysis techniques to utilize the data available from the incremental scans. Ultra-slow scanning would allow statistical use of the ${ }^{137} \mathrm{Cs}$ peak and other "weak" activities as well as contributing greater resolution. The present analyzer memory capacity is not great enough for ultra-high resolution scanning, as was shown in Figure 8 where it was possible to scan only one-third of the pin. 


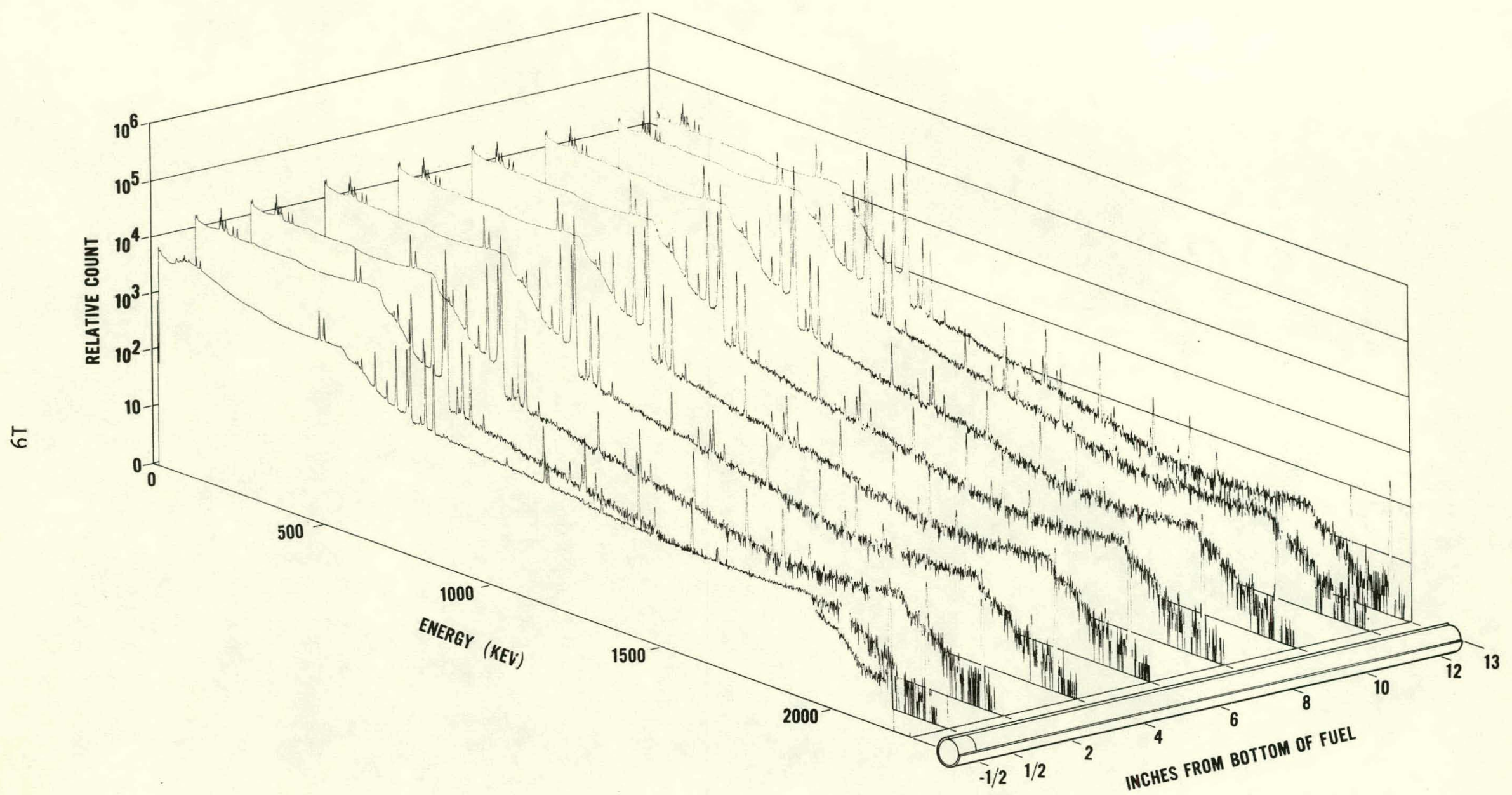

Neg 52158-1 
1. D. M. Holm, W. M. Sanders, L. L. Parker and H. D. Cowan, "Examination of Fast Reactor Fuel Elements with a Ge(Li) Anticoincidence Gamma-Ray Spectrometer," Proceedings of 16th Conference on Remote Systems Technology, p. 228, American Nuclear. Society, 1969.

2. D. M. Holm and W. M. Sanders, "A Semiconductor Anticoincidence Detector System," Radiochemical Methods of Analysis, vol. II, p. 81, International Atomic Energy Agency, Vienna, 1965.

3. B. K. Barnes, D. M. Holm, W. M. Sanders, D. D. Clinton and J. E. Swansen, "Techniques for Two-Dimensional Gamma-Ray Scanning of Reactor Fuel Element Sections," Nuclear Applications and Technology, vo1. 9, p. 746,1970 .

4. D. E. Christensen and E. S. Murphy, Determination of Relative Burnup by Gamma Scanning EBWR Fuel Rods, BNWL-653, Battelle-Northwest, Richland, Washington, April 1968.

5. S. Hiller, "Gamma-Spectrometric Burnup Determination in Reactor Fuel Rods," Kernticknik, vol. 12, p. 485, 1970.

6. D. E. Christensen, Unpublished Data. Battelle-Northwest, Richland, Washington, August 1970. (Gamma Scanning of PNL 2 Series FFTF Fuel Pins), BNWL-B-15.

7. W. L. Bunch, Shielding Calculations for Irradiated FTR Fuel, BNWL-342, Battelle-Northwest, Richland, Washington, December, 1966. 


\section{ACKNOWLEDGEMENTS}

Mechanical hardware design was performed by S. J. Ostrom who also directed installation of the mechanical portion. The assistance of J. L. Stringer in the circuit design of the original control module is gratefully acknowledged. R. D. Breneman acted as technical assistant during fabrication of the scanning system. J. W. Weber, of the Fuels Evaluation Section, WADCO, aided greatly in defining the needed system capabilities during design of the described system.

This paper is based on work performed under United States Atomic Energy Commission Contract AT(45-1)-1830. 


\section{DISTRIBUT ION}

No. of

Copies

OFFSITE

1

$\underline{\text { ȦEC Chicago Patent Group }}$

G. L. Lèe

2

AEC Division of Technical Information Extension

ONSITE

28

WADCO

R. B. Baker

G. A. Last

E. O. Ballard

R. D. Leggett

F. E. Bard

M. E. Mahan

D. C. Bullington

I. L. Metcalf

G. E. Culley

M. K. Millhollen

D. S. Dutt

L. A. Pember (5)

J. C. Gustafson

H. C. F. Ripfel

J. E. Hanson

W. E. Roake

E. N. Heck

D. 0. Shappard

R. J. Jackson

J. W. Weber (5)

$24 \quad$ Battelle-Northwest

D. E. Christensen

J. C. Crowe

G. J. Dau

L. C. Schmid.

J. R. Sletager

R. I. Smith

H. J. Svoboda

K. L. Swinth (10)

A. D. Vaughn

J. B. Vetrano

L. D. Williams

Technical Information

(3)

Technical Publication

(1) 